Check for updates

Cite this: RSC Adv., 2018, 8, 15604

Received 10th March 2018

Accepted 9th April 2018

DOI: 10.1039/c8ra02117a

rsc.li/rsc-advances

\section{Thermosensitive star polymer pompons with a core-arm structure as thermo-responsive controlled release drug carriers}

\author{
Na Xu, Xiaobei Huang, Guangfu Yin, (D)* Meijiao Bu, Ximing Pu, Xianchun Chen, \\ Xiaoming Liao and Zhongbing Huang
}

In contrast with traditional chemotherapy, controlled drug delivery systems provide many advantages. Herein, a thermosensitive star polymer pompon with a core-arm structure was synthesized using a grafting-on method as a thermo-responsive controlled release drug carrier. Single-chain cyclized/ knotted poly tetra(ethylene glycol) diacrylate (polyTEGDA) was used as the hydrophobic core, and thermosensitive linear poly( $N$-isopropylacrylamide-co- $N$-methylolacrylamide) (poly(NIPAM-co-NMA)) was selected as the hydrophilic arm. Below or above its lower critical solution temperature (LCST), the linear poly(NIPAM-co-NMA) grafted onto the polyTEGDA core adopted a stretched or curled status, respectively, then the drug could be loaded in or extruded out. The LCST of star polyTEGDA- $b-$ poly(NIPAM-CO-NMA) was adjusted to slightly above body temperature $\left(37^{\circ} \mathrm{C}\right)$. The antitumor drug doxorubicin (DOX) was successfully loaded into the pompons with a high loading capacity of $19.45 \%$. The cumulative release of DOX from loaded pompons in vitro for 72 hours was $71 \%$ and $20.7 \%$ at $42{ }^{\circ} \mathrm{C}$ and $37{ }^{\circ} \mathrm{C}$, respectively, indicating that the excellent temperature-controlled release characteristics result from the unique thermo-responsive extrusion effect. Moreover, DOX loaded polyTEGDA- $b$-poly(NIPAMco-NMA) pompons achieved better antitumor ability against ovarian carcinoma SKOV3 cells at $42{ }^{\circ} \mathrm{C}$ compared with that at $37{ }^{\circ} \mathrm{C}$. These results suggest that star polyTEGDA-b-poly(NIPAM-co-NMA) pompons have considerable promise as thermo-responsive controlled drug delivery carriers.

\section{Introduction}

In recent years, cancer has become one of the most disastrous diseases worldwide, and there were 17.5 million cancer cases and 8.7 million deaths in $2015 .^{1}$ The main approach in clinical treatment, chemotherapy, is restricted by some unavoidable defects. Most small molecule drugs come with severe side effects such as biological toxicity to normal tissues and cells, ${ }^{2}$ and protein and peptide drugs easily degrade in body circulation and exhibit lower bioavailability. ${ }^{3}$ The drug delivery system (DDS) has attracted more and more attention in recent years due to the characteristics of sustained and slowed release of drugs, which might be capable of relieving the damage to normal tissue by concentrated small molecule drugs or reducing the degradation and rapid renal clearance of polypeptide drugs. ${ }^{4}$ However, the release of loaded drugs from the ordinary DDS relies on the diffusion of drug molecules and/or the degradation of matrix material, and it is hard to release drugs in the lesion at the appropriate time. ${ }^{5}$

The stimuli-responsive drug delivery system (SDDS) was designed to be able to achieve concentrated release in the

College of Materials Science \& Engineering, Sichuan University, Chengdu 610065, China.E-mail: nico700@scu.edu.cn expected place and at the appropriate time under one or more stimuli, such as light, ${ }^{6,7} \mathrm{pH}^{8}$, enzymes, ${ }^{9}$ temperature ${ }^{7}$ and redox, ${ }^{8}$ and so could significantly increase the drug concentration in the lesions and avoid unnecessary drug release in normal tissues. Among all kinds of stimuli-responsive DDSs, the thermo-responsive DDS has tremendous application potential due to its excellent controllability and antiinterference ability. ${ }^{7}$ The most critical factor of the thermoresponsive DDS is that the molecular conformation of the carrier can be responsively changed at a specific temperature to allow the drugs to be loaded in or released out.

Poly( $N$-isopropylacrylamide) (PNIPAM) is a well-known thermosensitive polymer whose macromolecular chain contains both hydrophilic acylamino and hydrophobic isopropyl groups, and it undergoes a reversible phase transition from a swollen hydrated state to a shrunken dehydrated state in aqueous solution above its lower critical solution temperature (LCST) around $32{ }^{\circ} \mathrm{C}^{10}$ The LCST of PNIPAM can be precisely upregulated by introducing hydrophilic monomers and varying the molar ratio of monomers to adapt to biomedical applications. ${ }^{\mathbf{1 1 , 1 2}}$ Based on these features, several thermo-responsive drug delivery systems containing PNIPAM have been reported. ${ }^{\mathbf{1 3 , 1 4}}$ These PNIPAM based drug delivery systems can thermo-responsively release the encapsulated drugs, but there still exist some deficiencies for 
biomedical applications such as poorer stability, lower drugloading capacity and probable cytotoxicity.

Well-designed polymers with a "core-shell-periphery" structure, a hydrophobic core surrounded by a hydrophilic stabilizing shell, have been applied as gene transfection vectors and drug delivery carriers in past decades,${ }^{\mathbf{1 5 - 1 7}}$ and star polymers consisting of a core and several grafted arms have attracted much attention. ${ }^{18-23}$ Star polymers exhibit greater encapsulation capability due to their three-dimensional globular structures which provide looser drug loading spaces. ${ }^{24}$ Moreover, the hydrophilic arms covalently connected to the core can improve the colloid stability and aqueous solubility. ${ }^{25}$ In particular, star polymers can be endowed with a specific environmental responsiveness by adding correspondingly sensitive arms. ${ }^{26}$ There are three main approaches for star polymer synthesis: core-first, ${ }^{27,28}$ arm-first, ${ }^{29}$ and grafting-on..$^{30}$ The grafting approach is thought to be beneficial for the structural control of star polymers.

Here, a novel thermo-sensitive pompon with a core-arm structure was developed as a thermo-responsive controlled release drug carrier. Firstly, single-chain cyclized/knotted poly tetra(ethylene glycol) diacrylate (polyTEGDA) nanoparticles with multiple vinyl groups were synthesized as a core using a $\mathrm{Cu}^{0} \&$ $\mathrm{Cu}^{\mathrm{II}}$-mediated CRP method. ${ }^{31-33}$ Meanwhile, the LCST of PNIPAM was up-regulated to slightly above human body temperature by introducing hydrophilic $N$-methylolacrylamide (NMA) monomers. Then, the linear thermosensitive polymer poly(NIPAM-co-NMA) was grafted onto the polyTEGDA nanoparticles via Michael addition between the amino groups and vinyl groups to form a pompon-like star polyTEGDA- $b$-poly(NIPAM-co-NMA). Based on the analysis and adjustment of the thermo-response of polyTEGDA- $b$-poly(NIPAM-co-NMA), the drug-loading capacity and the drug-release behavior of the pompons at different temperatures were investigated in detail. The antitumor abilities of DOX loaded pompons were preliminarily studied by observing the inhibition rates of ovarian carcinoma SKOV-3 cells below and above the LCST. The results show that the novel DOX loaded pompons exhibit a desirable thermo-responsive drug-release behavior.

\section{Experimental section}

\subsection{Chemicals}

Tetra(ethylene glycol) diacrylate (TEGDA, 98\%), ethyl $\alpha$-bromoisobutyrate (EBriB, 98\%), copper(II) bromide $\left(\mathrm{CuBr}_{2}, 99 \%\right)$, $N, N, N^{\prime}, N^{\prime}, N^{\prime \prime}$-pentamethyldiethylenetriamine (PMDETA, 99\%), $N$-isopropylacrylamide (PNIPAM, 97\%) and $\mathrm{Cu}^{0}$-wire (diameter $1 \mathrm{~mm}$ ) were purchased from Sigma. 2-Aminoethanethiol hydrochloride (AET· $\mathrm{HCl}, 98 \%), \mathrm{N}$-methylolacrylamide (NMA, 98\%) and 2,2'-azobis(2-methylpropionitrile) (AIBN, 99\%, recrystallization) were purchased from Aladdin. Solvents were obtained from J\&K Chemical and used as received.

\subsection{Synthesis of star polymer polyTEGDA- $b$-poly(NIPAM-co- NMA)}

Firstly, hydrophobic polyTEGDA was synthesized via a $\mathrm{Cu}^{0} \& \mathrm{Cu}^{\mathrm{II}}$ mediated CRP method. The TEGDA, EBriB, PMDETA, and $\mathrm{CuBr}_{2}$ were dissolved in DMSO (in the molar feed ratio $100: 1: 0.8: 0.2$ ) with a monomer concentration of $0.5 \mathrm{M}$ at $25{ }^{\circ} \mathrm{C}$ under an atmosphere of nitrogen. $\mathrm{Cu}^{0}$-wire $(5 \mathrm{~cm})$ was immersed in conc. $\mathrm{HCl}$ and then thoroughly rinsed with acetone and water. Polymerization was conducted at $25{ }^{\circ} \mathrm{C}$ for the desired reaction time under stirring (600 rpm). The polymer was purified by reprecipitation in a considerable excess of diethyl ether.

Then, three monomer molar ratios (NIPAM : NMA $=6: 1$, $8: 1$ and $10: 1$ ) of amino-terminated poly(NIPAM-co-NMA) polymers were synthesized via free radical polymerization using AET $\cdot \mathrm{HCl}$ as a chain transfer agent. Monomer $\left(2.4 \times 10^{-2} \mathrm{~mol}\right)$, AET $\cdot \mathrm{HCl}\left(1.77 \times 10^{-4} \mathrm{~mol}\right)$ and AIBN $(2 \mathrm{mg})$ were dissolved in $30 \mathrm{ml}$ DMF. Oxygen in the solution was removed by bubbling nitrogen through it for $30 \mathrm{~min}$. The reaction was carried out under confined conditions at $70{ }^{\circ} \mathrm{C}$ for $6 \mathrm{~h}$. The product was purified by adding it dropwise to diethyl ether and filtering. The poly(NIPAM-co-NMA)- $\mathrm{NH}_{2}$ was dried in a vacuum.

The star polymer polyTEGDA- $b$-poly(NIPAM-co-NMA) was subsequently synthesized via Michael addition between the amino group on poly(NIPAM-co-NMA) and multiple vinyl groups on polyTEGDA. As is known, the synthesis of star polymers with macromolecular arms through the grafting-on method can be quite difficult because of the stereo-hindrance effect. In order to improve the grafting rate, the mass ratio of poly(NIPAM-co$\mathrm{NMA})-\mathrm{NH}_{2}$ and polyTEGDA was set as the excessive ratio of $100: 1$, and the reaction was carried out in DMSO for $24 \mathrm{~h}$ at room temperature. After that, the reaction solution was purified using a dialysis method ( $M_{\mathrm{w}}$ CO: $\left.20 \mathrm{kDa}\right)$ for $24 \mathrm{~h}$ and dried in a vacuum freeze drier for later use. The synthetic route of the star polymer polyTEGDA- $b$-poly(NIPAM-co-NMA) is illustrated in Fig. 1. Fig. $1 \mathrm{~b}$ is a schematic diagram of the formation process of star polyTEGDA- $b$-poly(NIPAM-co-NMA). In practical application, the PNIPAM arms often did not extend regularly and straight. The arms were intertwined, and it was this intertwining of the arms that provided the space for DOX loading.

\subsection{Polymer characterization}

The chemical structure of the polymers was confirmed using ${ }^{1} \mathrm{H}$ NMR. The polymers were dissolved in deuterated dimethylsulphoxide (DMSO-D6) and measured on a Varian Inova 400 $\mathrm{MHz}$ spectrometer. The molecular weight $\left(M_{\mathrm{w}}\right.$ and $\left.M_{\mathrm{n}}\right)$ and polydispersity index (PDI) of the polymers were measured using Gel Permeation Chromatography (Agilent 1260 Infinity MultiDetector GPC). Dynamic light scattering was performed to determine the size and distribution of polyTEGDA and star pompon polyTEGDA- $b$-poly(NIPAM-co-NMA) using a Zetasizer Nano Series Malvern Instrument (ZS90) at $37{ }^{\circ} \mathrm{C}$ and $42{ }^{\circ} \mathrm{C}$, respectively. The morphology of the DOX loaded pompons was observed with SEM (Hitachi S4800). Optical transmittances of the thermosensitive polymer aqueous solutions were measured with a Lambda Bio40 UV-Vis spectrometer (Perkin-Elmer) at $500 \mathrm{~nm}$ from $35{ }^{\circ} \mathrm{C}$ to $50{ }^{\circ} \mathrm{C}$.

\subsection{Cell culture}

SKOV3 (human ovarian carcinoma) and L929 (mice fibro-blasts) cell lines were obtained from West China Second University 

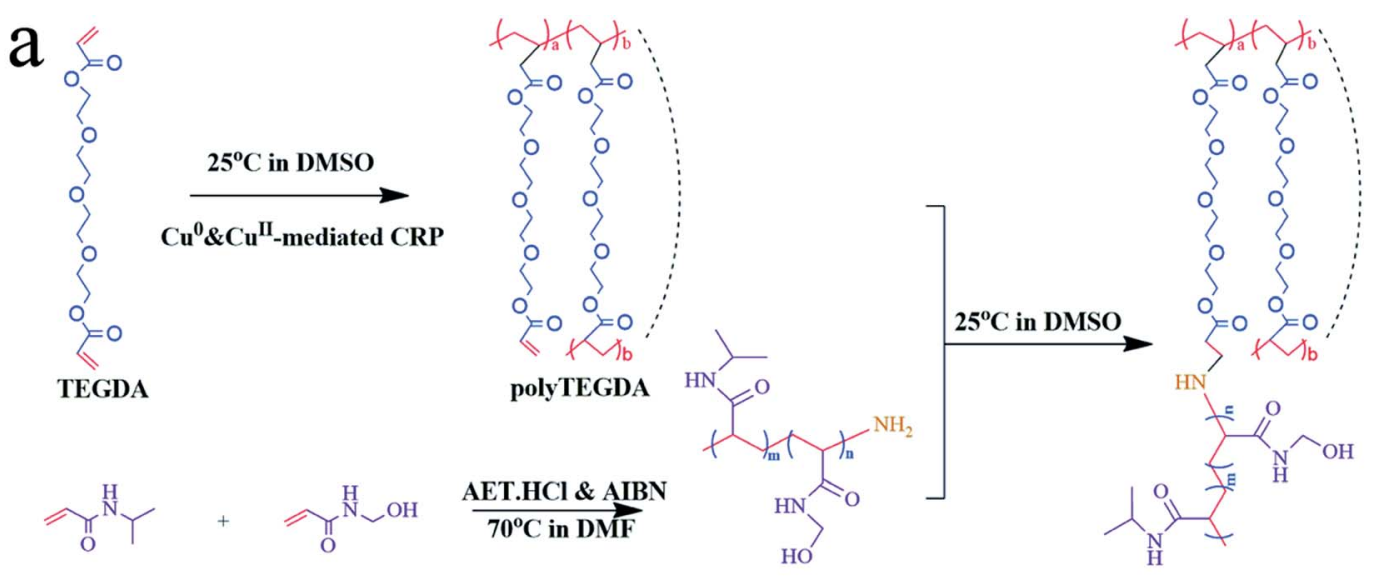

NIPAM

NMA

Poly(NIPAM-co-NMA)-NH

polyTEGDA-b-Poly(NIPAM-co-NMA)

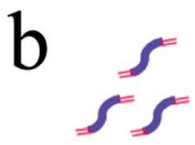

$\underset{\text { mediated CRP }}{\stackrel{\mathrm{Cu}^{0} \& \mathrm{Cu}^{\mathrm{II}}}{\longrightarrow}}$

TEGDA

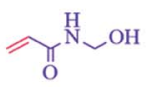

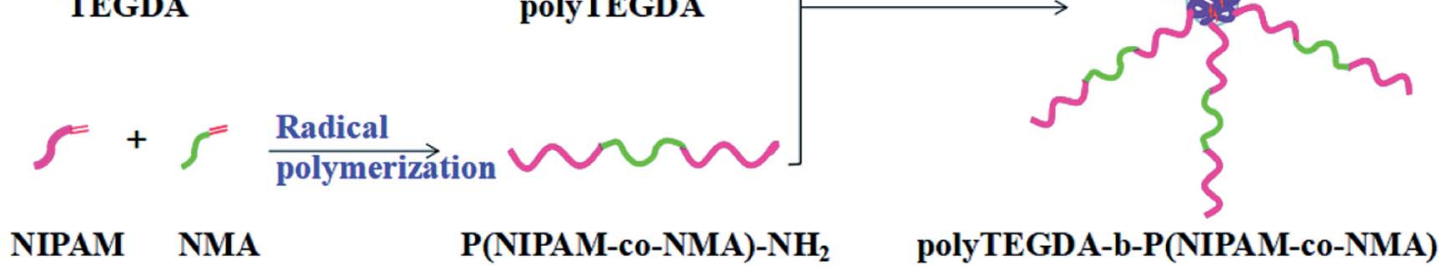

Fig. 1 (a) Synthesis route of star polyTEGDA-b-poly(NIPAM-co-NMA) pompons; (b) illustration of the formation process of the star polyTEGDAb-poly(NIPAM-co-NMA) pompons.

Hospital of Sichuan University (Chengdu, China). Cells were maintained in DMEM medium with $10 \%$ fetal bovine serum (Hyclone, USA) and $100 \mathrm{U} \mathrm{ml}^{-1}$ penicillin-streptomycin (Gibco BRL, Grand Island, NY), and incubated in a humidified atmosphere containing $5 \% \mathrm{CO}_{2}$ at $37{ }^{\circ} \mathrm{C}$.

\subsection{Cytotoxicity}

The cytotoxicity of poly(NIPAM-co-NMA)-NH $\mathrm{N}_{2}$ and polyTEGDA$b$-poly(NIPAM-co-NMA) against L929 cells was evaluated by MTT assay. L929 cells were seeded in a 96-well Lab-Tek chamber with a density of $1 \times 10^{4}$ per chamber and allowed to attach for $12 \mathrm{~h}$. Then, the cells were exposed to a series of concentrations of the polymers for 24,48 and $72 \mathrm{~h}$, respectively. After that, the cells were incubated with $20 \mu \mathrm{l} \mathrm{MTT}$ solution $\left(5 \mathrm{mg} \mathrm{ml}^{-1}\right)$ for a further 4 hours in the cell incubator. Then, the culture medium was discarded and $150 \mu \mathrm{l}$ DMSO was added per well to dissolve the purple insoluble material at the bottom. UV-absorbance values were measured using a microplate reader at $490 \mathrm{~nm}$. Cell viability was calculated in reference to a control group without exposure to test agents. All of the experiments were repeated thrice. The cytotoxicity comparison between poly(NIPAM-co-NMA)- $\mathrm{NH}_{2}$ and polyTEGDA- $b$-poly(NIPAM-co-NMA) was carried out according to the cell viabilities at an equal poly(NIPAM-coNMA) content.

\subsection{Synthesis of drug loaded pompons and drug thermo- responsive release behavior}

Drug loaded polymeric pompons were prepared via an $\mathrm{O} / \mathrm{W}$ emulsion method. Firstly, DOX $\cdot \mathrm{HCl}(8 \mathrm{mg})$ was dispersed in chloroform $\left(\mathrm{CHCl}_{3}\right)(4 \mathrm{ml})$ with TEA $(3 \mathrm{~mol} \mathrm{eq}$. to $\mathrm{DOX} \cdot \mathrm{HCl})$ to form an oil phase. Then, $20 \mathrm{mg}$ polymer was dissolved in deionized water $(20 \mathrm{ml})$ to form an aqueous phase. The oil phase was added dropwise to the aqueous phase with magnetic stirring and reacted overnight in darkness to remove the chloroform.

$1 \mathrm{mg}$ drug loaded pompons was dissolved in $2 \mathrm{ml}$ DMSO and the absorbance of the solution was determined using a Microplate reader at $490 \mathrm{~nm}$. The standard curve of UV-absorbance of the DOX/DMF solution $\left(y=20.215 x+0.0246, R^{2}=0.9984\right)$ was used to calculate the DOX concentration. The drug loading content was calculated according to the following formula:

$$
\mathrm{DLC}=\frac{W_{\text {DOX }}}{W_{\text {Total }}} \times 100 \%
$$

where $W_{\text {DOX }}$ is the weight of DOX in the pompons and $W_{\text {Total }}$ is the weight of the DOX loaded pompons.

Dialysis bags containing $1 \mathrm{ml}$ drug loaded pompon solution (polymer concentration: $1 \mathrm{mg} \mathrm{ml}^{-1}$ ) were immersed in $20 \mathrm{ml}$ distilled water. The release temperatures were set at $37^{\circ} \mathrm{C}$ and $42{ }^{\circ} \mathrm{C}$. An aliquot of $1 \mathrm{ml}$ was withdrawn from the solution at each pre-set time and replaced with fresh release medium. The 
released drug was quantified using UV-Vis spectroscopy at $490 \mathrm{~nm}$. The cumulative release was calculated via $W_{t} / W \times$ $100 \%$, where $W_{t}$ is the weight of the drug released from the pompons at time $t$, and $W$ is the total weight of the drug loaded into the pompons.

\subsection{Antitumor ability in vitro of DOX loaded pompons}

The antitumor ability in vitro of DOX loaded star pompon polyTEGDA- $b$-poly(NIPAM-co-NMA) was confirmed using an MTT assay. Test samples containing different concentrations of pompon were incubated with SKOV-3 cells for $24 \mathrm{~h}$ at $37^{\circ} \mathrm{C}$ and $42{ }^{\circ} \mathrm{C}$, and the related cell viabilities were measured.

\section{Results and discussion}

\subsection{Preparation and characterization of polyTEGDA}

PolyTEGDA was synthesized using a $\mathrm{Cu}^{0} \& \mathrm{Cu}^{\mathrm{II}}$-mediated CRP method. During the synthesis process, the GPC traces showed a unimodal peak and the peak moved steadily to the left $(T<$ $2.5 \mathrm{~h}$ ). After 2.5 hours, it was observed that the GPC trace exhibits a near-symmetrical unimodal peak which indicates the successful synthesis of single-chain cyclized/knotted macromolecules without any intermolecular combination (Fig. 2a). The final polyTEGDA had a Mn of $9.9 \mathrm{kDa}$ with a PDI of 1.14 .

${ }^{1} \mathrm{H}$ NMR spectroscopy was employed to confirm the chemical structure of the resultant polyTEGDA. As shown in Fig. $2 \mathrm{~b}$, the chemical shifts of hydrogen protons at $3.65 \mathrm{ppm}$ and $4.31 \mathrm{ppm}$ are ascribed to the methylene protons of $-\mathrm{CH}_{2}-$ O- and $-\mathrm{COOCH}_{2}-$. Three characteristic signal peaks $(\delta=$ $5.80,6.05$ and $6.43 \mathrm{ppm}$ ) correspond to the vinyl groups of polyTEGDA and pendent vinyl conversion reached $39.11 \%$ (Fig. 2b). It was shown that there were on average 16 vinyl groups in each polyTEGDA molecule. PolyTEGDA with multiple vinyl groups was successfully synthesized via $\mathrm{Cu}^{0}$ \& $\mathrm{Cu}^{\mathrm{II}}$-mediated CRP method.

\subsection{Synthesis of poly(NIPAM-co-NMA)- $\mathrm{NH}_{2}$ and regulation of LCST}

Amino-terminated polymer poly(NIPAM-co-NMA)- $\mathrm{NH}_{2}$ was synthesized via radical polymerization. By adjusting the molar feed ratio of NIPAM/NMA, three kinds of thermosensitive polymer with different LCSTs were obtained. The ${ }^{1} \mathrm{H}$ NMR spectrum of poly(NIPAM-co-NMA)-NH $\mathrm{N}_{2}$ showed the characteristic peak at $1.05 \mathrm{ppm}$ due to the presence of $-\mathrm{CH}_{3}$ protons in NIPAM. The peak at $5.44 \mathrm{ppm}$ corresponding to $-\mathrm{CH}_{2}-\mathrm{OH}$ in NMA suggested the incorporation of NMA molecules into the chain. The peak at $7.98 \mathrm{ppm}$ corresponds to $-\mathrm{NH}$ protons in NIPAM and NMA. The ${ }^{1} \mathrm{H}$ NMR data confirmed the successful synthesis of poly(NIPAM-co-NMA)$\mathrm{NH}_{2}$ (Fig. 3a).

The LCST was defined as the temperature producing half of the total decrease in optical transmittance. The LCST of poly(NIPAM-co-NMA)- $\mathrm{NH}_{2}$ was determined by measuring the optical transmittance from $35{ }^{\circ} \mathrm{C}$ to $50{ }^{\circ} \mathrm{C}$. PNIPAM itself showed a LCST near $32{ }^{\circ} \mathrm{C}$. A significant LCST rise could be observed when NIPAM was copolymerized with hydrophilic NMA. The LCSTs of the linear polymer arms with different molar feed ratios of NIPAM/NMA(6:1, $8: 1,10: 1)$ were $40.3{ }^{\circ} \mathrm{C}, 39.6{ }^{\circ} \mathrm{C}$, and $38.7{ }^{\circ} \mathrm{C}$, respectively (Fig. 3b). It was reported that hydrophilic monomers introduced to PNIPAM can disturb the dehydration of PNIPAM and increase the energy needed for precipitation..$^{34}$ As the more hydrophilic component, NMA copolymerizing with NIPAM can increase the thermal energy required for the precipitation of PNIPAM. Therefore, the LCST of the copolymer is higher than that of pure PNIPAM. Increasing the mole fraction of NMA can shift the LCST to higher temperature. To avoid premature phase transition of the star polymer under normal physiological conditions $\left(37^{\circ} \mathrm{C}\right)$, the linear thermosensitive polymer with a LCST of $40.3{ }^{\circ} \mathrm{C}$ (NIPAM/NMA molar feed ratio of $6: 1$ ) was chosen as the arms of the star polymer.
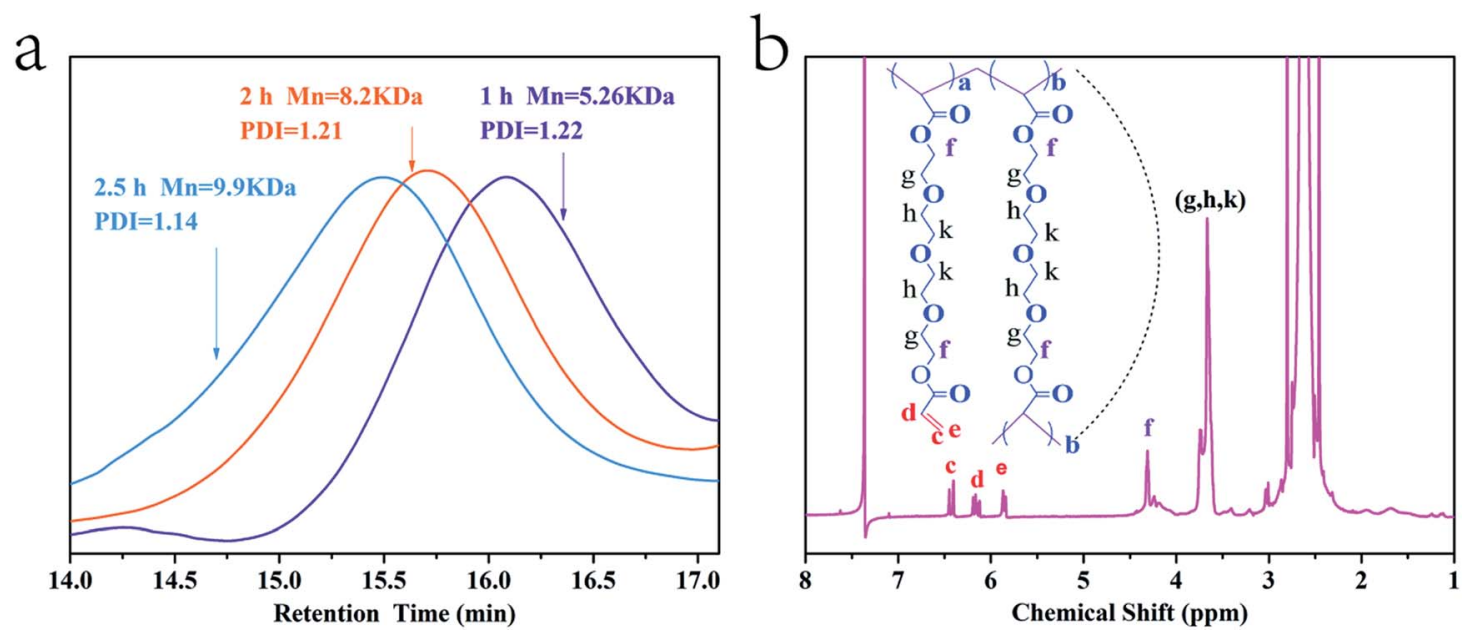

Fig. 2 (a) Time dependency of the composition of the polymerization mixtures monitored by GPC with a retention time detector for the $\mathrm{Cu}{ }^{0} \&$

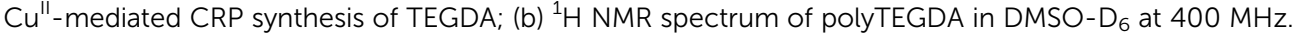



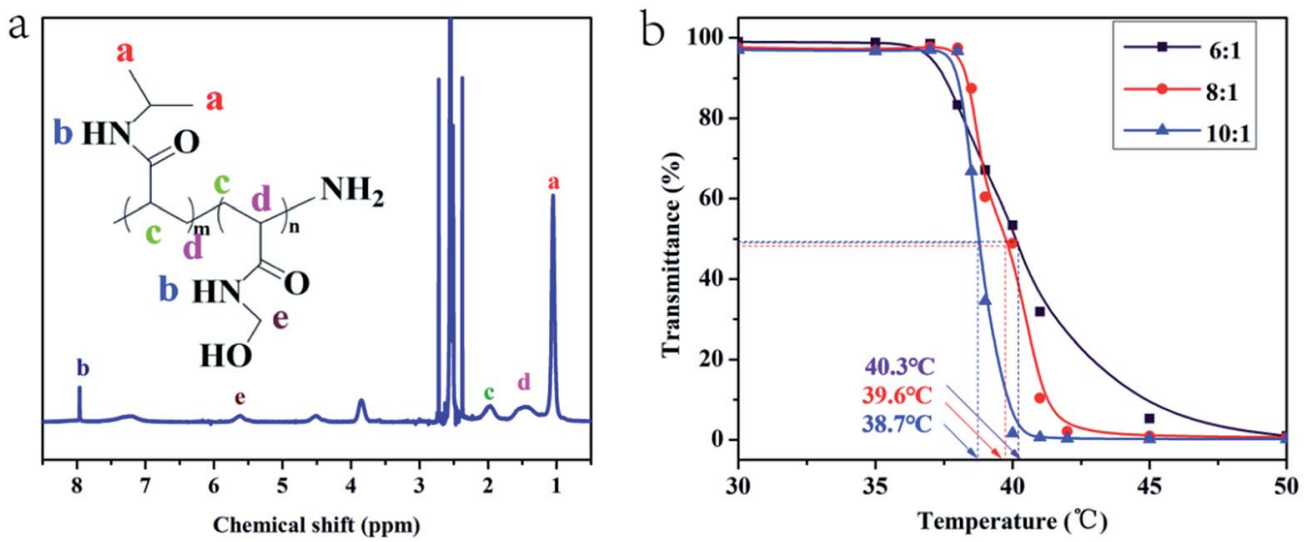

Fig. 3 (a) ${ }^{1} \mathrm{H}$ NMR spectrum of poly(NIPAM-co-NMA)- $\mathrm{NH}_{2}$ in DMSO- $\mathrm{D}_{6}$ at $400 \mathrm{MHz}$; (b) thermosensitive behavior of linear poly(NIPAM-coNMA) $-\mathrm{NH}_{2}$ with three molar ratios of NIPAM and NMA.

\subsection{Synthesis and thermosensitivity of polyTEGDA- $g$ - poly(NIPAM-co-NMA) pompons}

The chemical structure of the star polymer was confirmed by ${ }^{1} \mathrm{H}$ NMR spectroscopy. In the ${ }^{1} \mathrm{H}$ NMR spectrum (Fig. 4a), the characteristic chemical shift at $4.13 \mathrm{ppm}$ was assigned to methylene protons $\left(-\mathrm{COOCH}_{2}-\right)$ in polyTEGDA. The chemical shift of methyl proton $\left(-\mathrm{CH}\left(\mathrm{CH}_{3}\right)_{2}\right)$ in poly(NIPAM-co-NMA)$\mathrm{NH}_{2}$ appeared at $1.24 \mathrm{ppm}$, and all three characteristic signal peaks of the vinyl groups $(\delta=5.80,6.05$ and $6.43 \mathrm{ppm})$ nearly disappeared. ${ }^{1} \mathrm{H}$ NMR spectroscopy showed that the vinyl groups of polyTEGDA reacted with the amino groups of poly(NIPAM-co-NMA). The hydrophilic arms were successfully grafted onto the hydrophobic core to form a star polymer pompon with a "core-arm" structure.

The number average molecular weights of poly(NIPAM-coNMA)- $\mathrm{NH}_{2}$ (NIPAM/NMA = $6: 1$ ), polyTEGDA and polyTEGDA$g$-poly(NIPAM-co-NMA) were determined to be $5.3 \mathrm{kDa}$ with a PDI of 1.21, $9.9 \mathrm{kDa}$ with a PDI of 1.14 , and $25.6 \mathrm{kDa}$ with a PDI of 1.07, respectively (Fig. 4b). The significant Mn increase of polyTEGDA- $g$-poly(NIPAM-co-NMA) relative to poly(NIPAM-co-
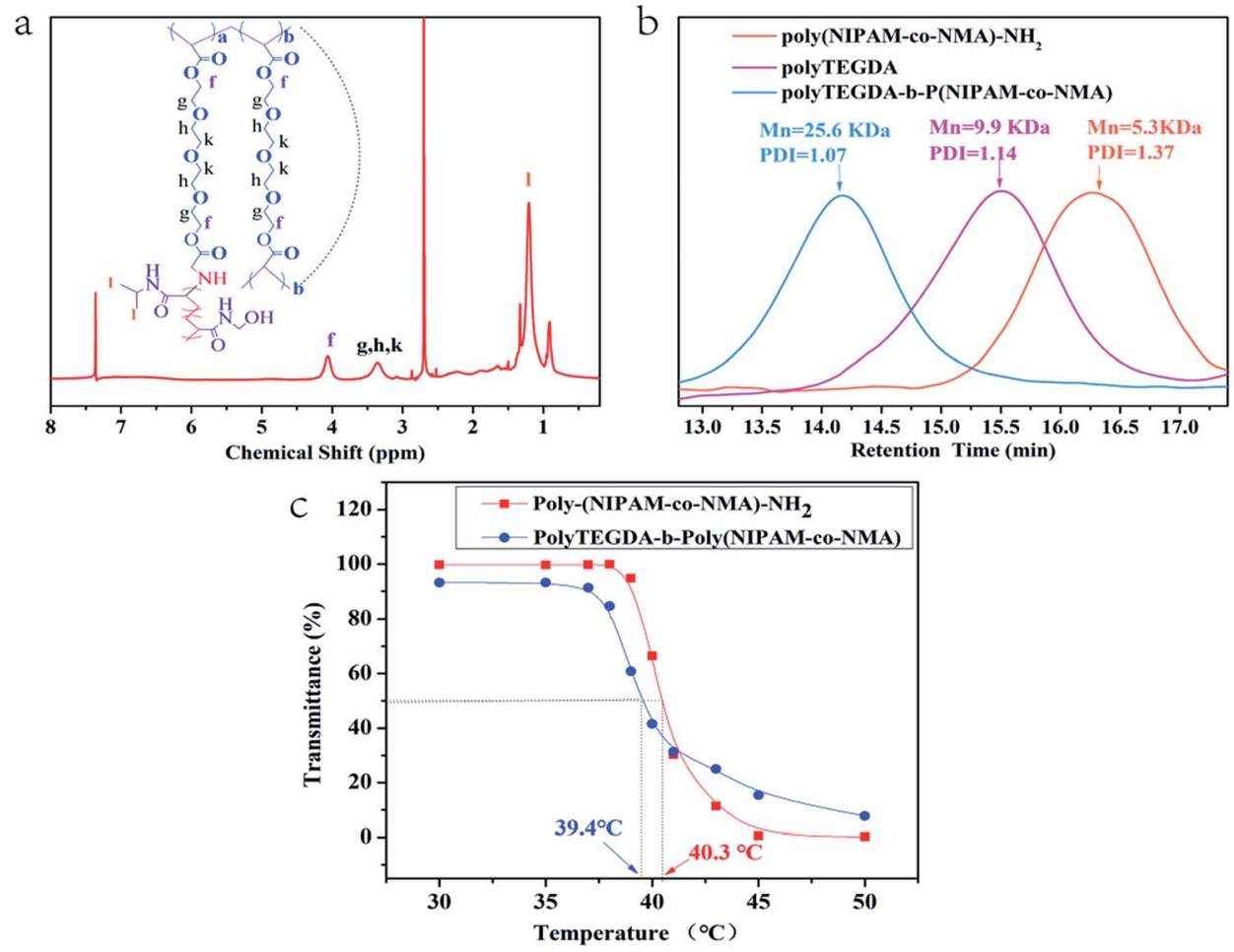

Fig. 4 (a) ${ }^{1} \mathrm{H}$ NMR spectrum of star polyTEGDA- $b$-poly(NIPAM-co-NMA) in DMSO-D6 at 400 MHz; (b) GPC traces of poly(NIPAM-co-NMA)$\mathrm{NH}_{2}$, polyTEGDA and star polyTEGDA- $b$-poly(NIPAM-CO-NMA); (c) thermosensitive behaviors of poly(NIPAM-CO-NMA)-NH 2 (NIPAM/NMA = $6: 1$ ) and star polyTEGDA-b-poly(NIPAM-CO-NMA). 

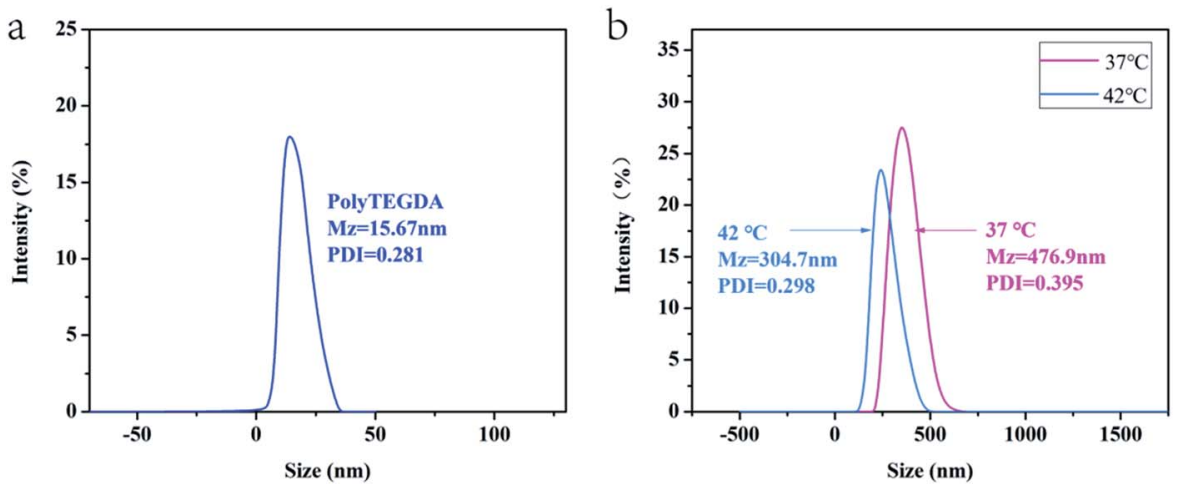

Fig. 5 Characterization of size and distribution of polyTEGDA nanoparticles and star polyTEGDA- $b$-poly(NIPAM-co-NMA) pompons using dynamic light scattering (DLS). (a) PolyTEGDA nanoparticles in DMSO at $37^{\circ} \mathrm{C}$; (b) star polyTEGDA- $b$-poly(NIPAM-co-NMA) pompons in aqueous media at $37^{\circ} \mathrm{C}$ and $42^{\circ} \mathrm{C}$.

NMA)- $\mathrm{NH}_{2}$ and polyTEGDA indicates the successful synthesis of polyTEGDA-g-poly(NIPAM-co-NMA). The average number of arms was around 3, calculated from the change in Mn.

The thermo-sensitivity of the star pompons is shown in Fig. 4c. Compared to the corresponding thermosensitive polymer poly(NIPAM-co-NMA)- $\mathrm{NH}_{2}$, the LCST of the prepared star pompons is lowered down to $39.4{ }^{\circ} \mathrm{C}$ owing to the addition of the hydrophobic core, just within the expected range slightly above body temperature $\left(37^{\circ} \mathrm{C}\right)$.

DLS results of the cores and star pompons are shown in Fig. $5 \mathrm{a}$ and $\mathrm{b}$. The hydrophobic core has a smaller average particle size of $15.67 \mathrm{~nm}$ with a PDI of 0.281 . The smaller size indicates that the single-chain cyclized/knotted polyTEGDA nanoparticles possess a compact inner structure. In contrast,
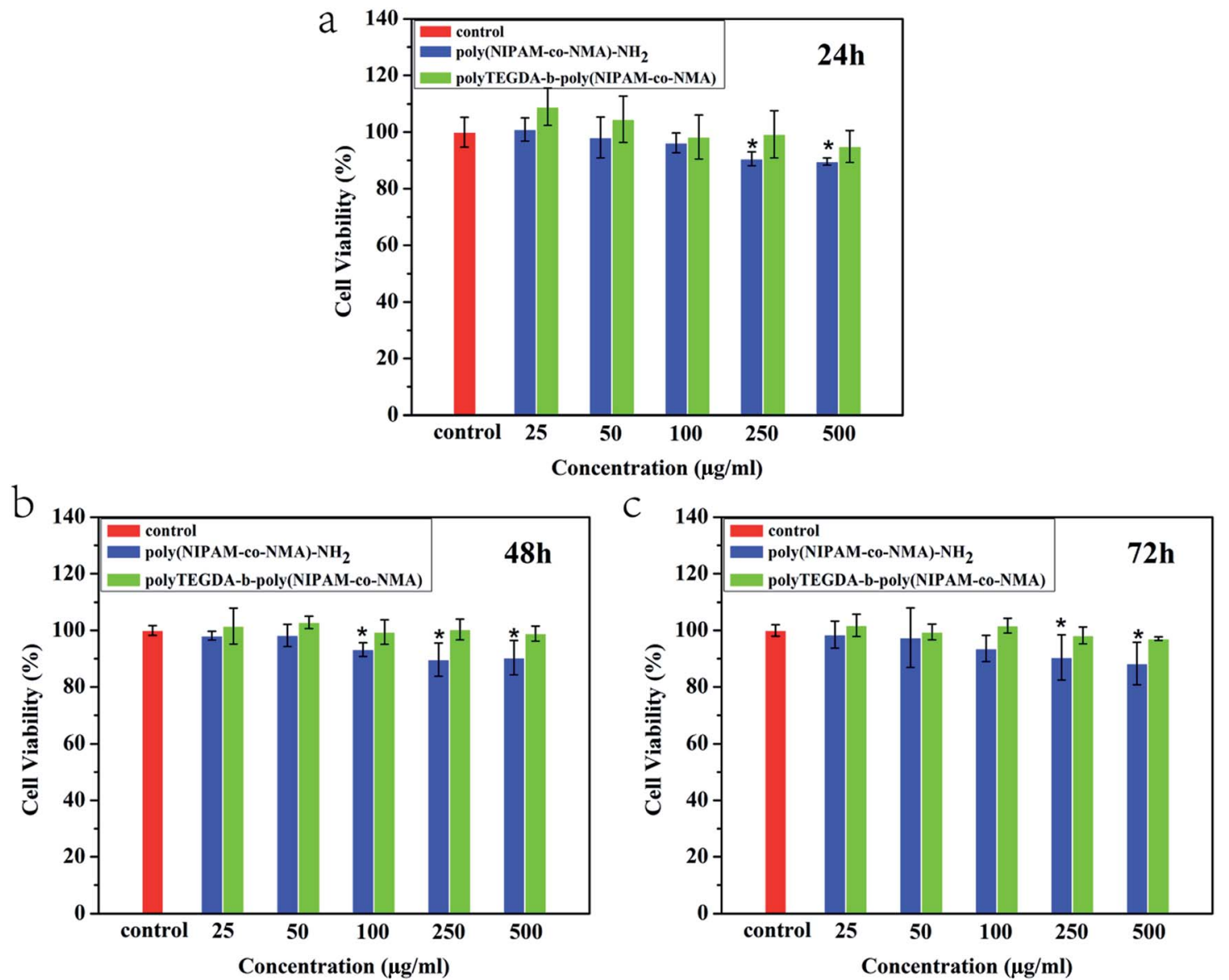

Fig. 6 The cytotoxicity of poly(NIPAM-co-NMA)-NH 2 and polyTEGDA-b-poly(NIPAM-co-NMA) against L929 after incubation for (a) 24 h; (b) $48 \mathrm{~h}$; and (c) $72 \mathrm{~h}$. 

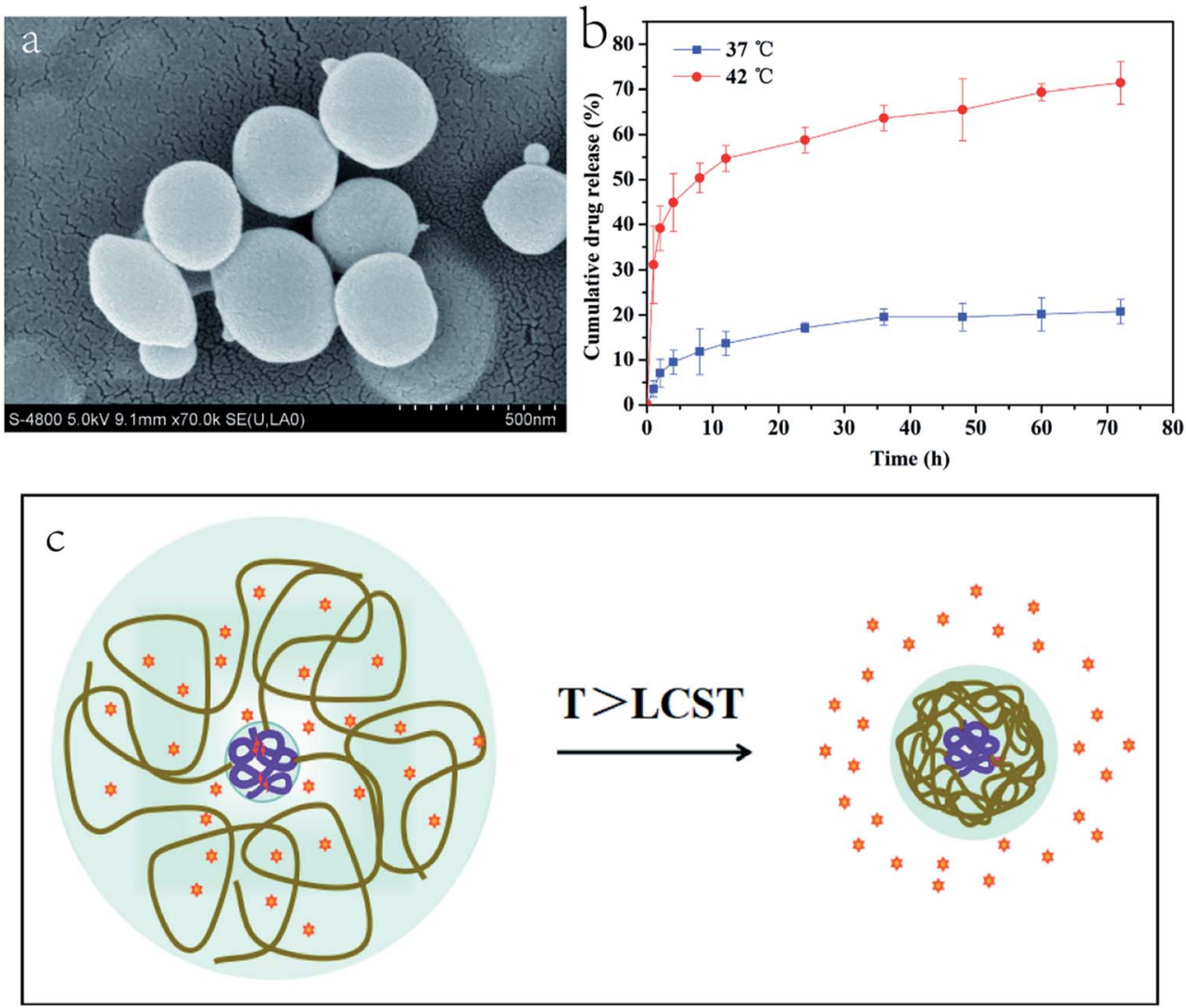

Fig. 7 (a) SEM photograph of drug loaded polyTEGDA-b-poly(NIPAM-co-NMA) pompons; (b) in vitro cumulative release of DOX from the star pompons at $37^{\circ} \mathrm{C}$ and $42^{\circ} \mathrm{C}$; (c) diagrammatic sketch for the mechanism of the controlled drug release from the thermo-responsive pompons.

the average diameter of the star pompons is $476.9 \mathrm{~nm}$ with a PDI of 0.395 at $37{ }^{\circ} \mathrm{C}$. The obvious size increase of star pompons relative to the core might result from the introduction of the hydrophilic arms.

DLS results for star pompons at different temperatures are shown in Fig. 5b. When the temperature was lower than the LCST, the amide groups on the arms could form intermolecular hydrogen bonds with water molecules. These water molecules were arranged in an orderly manner around the chains and formed a layer of solvation shell, and the arms showed a stretched hydrated state. As the temperature was raised to $42{ }^{\circ} \mathrm{C}$ (higher than the LCST), the average particle size was reduced to $304.7 \mathrm{~nm}$ with a PDI of 0.298 (Fig. 5a). The hydrogen bonds between the arm molecules and water molecules were destroyed by the intensified molecular thermal motion, and the solvation shell was broken. Meanwhile, some hydrogen bonds between the intramolecular and/or intermolecular amide groups could be formed, causing the molecule chain of the arms to be curled and to display a shrunken dehydrated state. This result revealed the thermo-responsive behavior of the prepared pompons.

\subsection{Cytotoxicity}

The cytotoxicities of blank poly(NIPAM- $c o-\mathrm{NMA})-\mathrm{NH}_{2}$ and the star pompons polyTEGDA- $g$-poly(NIPAM-co-NMA) with an equivalent poly(NIPAM-co-NMA) content against L929 cells are shown in Fig. 6. After incubation with L929 cells for 24 h, 48 h and $72 \mathrm{~h}$, the blank poly(NIPAM- $c o$-NMA)- $\mathrm{NH}_{2}$ exhibited a certain cytotoxicity at the higher concentrations, but the star polyTEGDA- $b$-poly(NIPAM-co-NMA) showed negligible cytotoxicity even at high concentrations, as proven by the high cell viability $(\sim 100 \%)$.

\subsection{Drug loading and thermo-responsive release behaviors of the pompons}

DOX as the model drug was loaded into the star pompons. The SEM image (Fig. 7a) showed that the DOX loaded star pompons showed a regular spherical morphology with a diameter of about $350-450 \mathrm{~nm}$. The drug loading capacity (LC) of the DOX loaded pompons was $19.45 \%$. When the temperature was below the LCST, the stretched chain arms grafted onto the core could intertwine into a three-dimensional network to provide a looser drug loading space. The DOX would be predominantly loaded into this network, and few DOX molecules could get into the innermost core of polyTEGDA due to its smaller size and compact structure.

The thermo-responsive drug release behaviour of the star pompons was studied using a dialysis method at $37{ }^{\circ} \mathrm{C}$ and $42{ }^{\circ} \mathrm{C}$. The drug release profiles (Fig. $7 \mathrm{~b}$ ) showed the drastic change in drug release rate from star pompons at the temperatures below and above the LCST. The star pompons could stay stable at the temperature of $37^{\circ} \mathrm{C}$ (below the LCST); only a very 
small amount of the loaded drug (about 20.7\%) leaked out of the pompons via the diffusion of drug molecules in $72 \mathrm{~h}$. Quite a lot of the drug (about 79.3\%) still remained in the star pompons. Dissimilarly, the drug release rate dramatically increased when the temperature was increased to $42{ }^{\circ} \mathrm{C}$ (above the LCST), and about $71 \%$ of the loaded drug was released from the pompons in $72 \mathrm{~h}$. As the temperature was raised from $37{ }^{\circ} \mathrm{C}$ to $42{ }^{\circ} \mathrm{C}$, the three-dimensional network composed of the intertwined arms could be converted from the relaxed hydrated state to the shrunk dehydrated state, and the drugs dissolved in solution within the network were extruded out. The drug release from these thermosensitive star pompons is mainly reliant on the extrusion effect resulting from the volume shrinkage above the LCST, and so the star polyTEGDA- $g$-poly(NIPAM-co-NMA) pompons perform with higher stability and controllability as a controlled release drug carrier.

\subsection{Antitumor ability in vitro against SKOV-3 cells}

The antitumor ability of DOX-loaded pompons in vitro against ovarian carcinoma SKOV3 cells is shown in Fig. 8. At the lower pompon concentrations (equivalent to a DOX concentration $<10^{-1} \mu \mathrm{g} \mathrm{ml} \mathrm{m}^{-1}$ ), the DOX loaded pompons exhibited similar cancer cell inhibition capacities without obvious difference at $37{ }^{\circ} \mathrm{C}$ and $42{ }^{\circ} \mathrm{C}$. This might be attributed to the extremely low drug concentration; even if all of the DOX had been released from an inadequate quantity of pompons, it was less than the effective inhibitory concentration (EIC). It is consistent with literature reports that cell viability would be higher than $80 \%$ at lower free DOX concentrations (less than $10^{-1} \mu \mathrm{g} \mathrm{ml}^{-1}$ ) when the SKOV3 cells were co-cultured with free DOX. ${ }^{35}$ In contrast, the DOX loaded pompons with higher concentrations demonstrated much stronger antitumor ability at $42{ }^{\circ} \mathrm{C}$ than at $37{ }^{\circ} \mathrm{C}$, profiting from the rapid thermo-responsive release at the temperature above the LCST. Consequently, these thermosensitive star pompons have potential as desirable thermo-responsive drug carriers for cancer therapy.

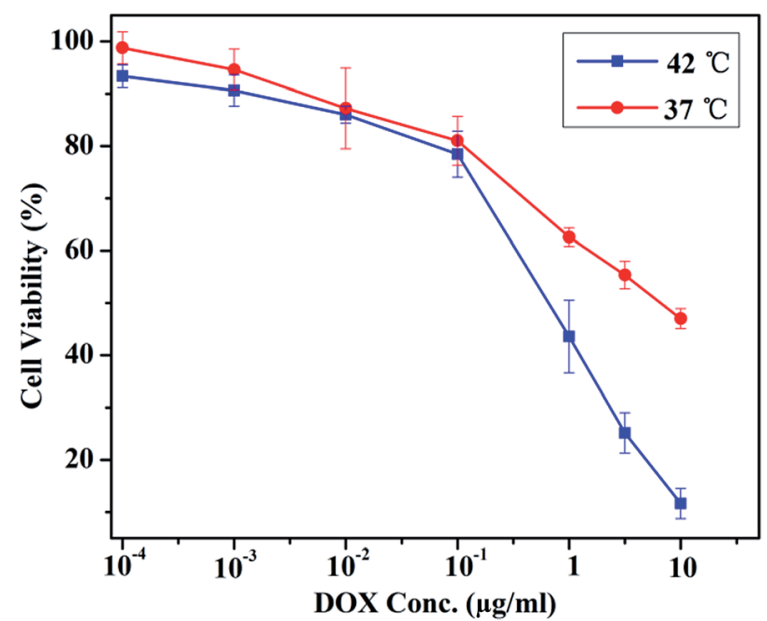

Fig. 8 Antititumor ability of DOX loaded pompons against SKOV3 cells after co-culturing for $24 \mathrm{~h}$ at $37^{\circ} \mathrm{C}$ and $42{ }^{\circ} \mathrm{C}$.

\section{Conclusions}

A novel thermosensitive star pompon, polyTEGDA- $b$-poly(NIPAM-co-NMA), with polyTEGDA as the hydrophobic core and poly(NIPAM-co-NMA) as the hydrophilic arms, has been synthesized using a grafting-on method. The single-chain cyclized/knotted polyTEGDA core appeared as a compact nanoparticle with an average diameter of $15.67 \mathrm{~nm}$, and linear thermosensitive poly(NIPAM-co-NMA) with a lower critical solution temperature (LCST) was grafted onto the core and subsequently intertwined into a three-dimensional network. The thermo-responsive performance of the star pompons could be modified by adjusting the LCST of poly(NIPAM-co-NMA) via the hydrophilic monomer NMA. At the temperature below or above the LCST of the star pompons, the poly(NIPAM-co-NMA) molecular chains intertwined in a three-dimensional network existed in the form of the relaxed hydrated state or the shrunk dehydrated state, respectively, and so the drug could be loaded in or extruded out. Importantly, the drug release from these thermosensitive star pompons was mainly reliant on the extrusion effect resulting from the volume shrinkage of the temperature above the LCST, rather than the diffusion of drug molecules and/or the degradation of the matrix in the ordinary DDS. The experimental results show that the DOX loaded star pompons with a high drug loading capability of $19.45 \%$ demonstrated much higher drug release rates at $42{ }^{\circ} \mathrm{C}$ (above their LCST of $39.4{ }^{\circ} \mathrm{C}$ ) than at $37{ }^{\circ} \mathrm{C}$ (normal human body temperature), and then exhibited much stronger antitumor ability against ovarian carcinoma SKOV3 cells in vitro. This study demonstrates that this novel polyTEGDA- $b$-poly(NIPAMco-NMA) star pompon displays higher drug loading capability and controllable thermo-response and has considerable promise as a thermo-responsive controlled drug delivery carrier.

\section{Conflicts of interest}

There are no conflicts to declare.

\section{Acknowledgements}

This work has been supported by the National Natural Science Foundation of China (project No. 51372157).

\section{References}

1 C. Fitzmaurice, C. Allen, R. M. Barber, L. Barregard, Z. A. Bhutta, H. Brenner, D. J. Dicker, O. Chimedorchir, R. Dandona and L. Dandona, JAMA Oncology, 2017, 3, 524.

2 T. M. Allen and P. R. Cullis, Science, 2004, 303, 1818.

3 L. Tang, A. M. Persky, G. Hochhaus and B. Meibohm, J. Pharm. Sci., 2004, 93, 2184.

4 K. Hörmann and A. Zimmer, J. Controlled Release, 2016, 223, 85-98.

5 N. Huebsch, C. J. Kearney, X. Zhao, J. Kim, C. A. Cezar, Z. Suo and D. J. Mooney, Proc. Natl. Acad. Sci. U. S. A., 2014, 111, 9762-9767. 
6 Y. T. Chang, P. Y. Liao, H. S. Sheu, Y. J. Tseng, F. Y. Cheng and C. S. Yeh, Adv. Mater., 2012, 24, 3309-3314.

7 T. Rong, H. D. Hemmati, L. Robert and D. S. Kohane, J. Am. Chem. Soc., 2012, 134, 8848.

$8 \mathrm{H}$. Zheng and S. Che, RSC Adv., 2012, 2, 4421-4429.

9 A. Bernardos, L. Mondragón, E. Aznar, M. D. Marcos, R. Martínezmáñez, F. Sancenón, J. Soto, J. M. Barat, E. Pérezpayá and C. Guillem, ACS Nano, 2010, 4, 6353-6368.

10 J. F. Lutz, Ö. Akdemir and A. Hoth, J. Am. Chem. Soc., 2006, 128, 13046-13047.

11 J. F. Lutz and A. Hoth, Macromolecules, 2006, 39, 133-142.

12 G. Chen and A. S. Hoffman, Nature, 1995, 373, 49.

13 L. Mäkinen, D. Varadharajan, H. Tenhu and S. Hietala, Macromolecules, 2016, 49, 986-993.

14 D. Das, P. Ghosh, A. Ghosh, C. Haldar, S. Dhara, A. B. Panda and S. Pal, ACS Appl. Mater. Interfaces, 2015, 7, 14338.

15 N. Amirmahani, N. O. Mahmoodi, M. M. Galangash and A. Ghavidast, J. Ind. Eng. Chem., 2017, 21-34.

16 Y. Tahara, S. A. Mukai, S. Sawada, Y. Sasaki and K. Akiyoshi, Adv. Mater., 2015, 27, 5080.

17 D. Peer, J. M. Karp, S. Hong, O. C. Farokhzad, R. Margalit and R. Langer, Nat. Nanotechnol., 2007, 2, 751-760.

18 W. Wang, L. Zhang, M. Liu, Y. Le, S. Lv, J. Wang and J. F. Chen, RSC Adv., 2016, 6, 6368-6377.

19 J. Burke, R. Donno, R. D’Arcy, S. Cartmell and N. Tirelli, Biomacromolecules, 2017, 18, 728-739.

20 L. Y. Li, W. D. He, J. Li, B. Y. Zhang, T. T. Pan, X. L. Sun and Z. L. Ding, Biomacromolecules, 2010, 11, 1882-1890.

21 X. Zhou, Q. Zheng, C. Wang, J. Xu, J. P. Wu, T. B. Kirk, D. Ma and W. Xue, ACS Appl. Mater. Interfaces, 2016, 8, 12609.
22 T. Liu, W. Xue, B. Ke, M. Q. Xie and D. Ma, Biomaterials, 2014, 35, 3865-3872.

23 Y. Pu, L. Zhang, H. Zheng, B. He and Z. Gu, Macromol. Biosci., 2014, 14, 289-297.

24 W. Wu, W. Wang and J. Li, Prog. Polym. Sci., 2015, 46, 55-85.

25 J. M. Ren, T. G. Mckenzie, Q. Fu, E. H. Wong, J. Xu, Z. An, S. Shanmugam, T. P. Davis, C. Boyer and G. G. Qiao, Chem. Rev., 2016, 116, 6743-6836.

26 F. Xu, J. W. Xu, B. X. Zhang and L. Yan-Ling, AIChE J., 2015, 61, 35-45.

27 A. O. Burts, A. X. Gao and J. A. Johnson, Macromol. Rapid Commun., 2014, 35, 168-173.

28 S. Muthukrishnan, F. Plamper, A. Hideharu Mori and A. H. E. Muller, Macromolecules, 2005, 38, 10631-10642.

29 P. Liu, E. Landry, Z. Ye, H. Joly, W. Wang and B. Li, Macromolecules, 2011, 44, 4125-4139.

30 Z. Qiang, G. Z. Li, C. R. Becer and D. M. Haddleton, Chem. Commun., 2012, 48, 8063-8065.

31 Y. Zheng, H. Cao, B. Newland, Y. Dong, A. Pandit and W. Wang, J. Am. Chem. Soc., 2011, 133, 13130-13137.

32 T. Zhao, Y. Zheng, J. Poly and W. Wang, Nat. Commun., 2013, 4, 1-8.

33 Y. Gao, D. Zhou, T. Zhao, X. Wei, S. Mcmahon, J. O. K. Ahern, W. Wang, U. Greiser, B. J. Rodriguez and W. Wang, Macromolecules, 2015, 48, 6882-6889.

34 Y. G. Takei, T. Aoki, K. Sanui, N. Ogata, T. Okano and Y. Sakurai, Bioconjugate Chem., 1993, 4, 341-346.

35 Q. Zhang, H. Chi, M. Tang, J. Chen, G. Li, Y. Liu and B. Liu, RSC Adv., 2016, 6, 87258-87269. 